\title{
Carbonated soft drinks induce oxidative stress and alter the expression of certain genes in the brains of Wistar rats
}

\author{
ADEL EL-TERRAS ${ }^{1-3}$, MOHAMED MOHAMED SOLIMAN ${ }^{1,4,5}$, ADEL ALKHEDAIDE ${ }^{4}$, \\ HOSSAM FOUAD ATTIA ${ }^{1,4,6}$, ABDULLAH ALHARTHY ${ }^{1,7}$ and ABDEL ELAH BANAJA ${ }^{8}$ \\ ${ }^{1}$ Al-Saedan Research Chair for Genetic Behavioral Disorders; ${ }^{2}$ Biotechnology and Genetic Engineering Unit, \\ Scientific Research Deanship, Taif University, Taif, Mecca 21421, Kingdom of Saudi Arabia; \\ ${ }^{3}$ Department of Genetics, Faculty of Agriculture, Cairo University, Cairo 12613, Egypt; \\ ${ }^{4}$ Medical Laboratory Department, Faculty of Applied Medical Sciences, Taif University, Turabah, Mecca 21411, \\ Kingdom of Saudi Arabia; Departments of ${ }^{5}$ Biochemistry and ${ }^{6}$ Histology, Faculty of Veterinary Medicine, \\ Benha University, Benha, Qalyubia Governorate 13736, Egypt; ${ }^{7}$ College of Medicine, Taif University; \\ ${ }^{8}$ Department of Biology, Faculty of Science, Taif University, Taif, Mecca 11111, Kingdom of Saudi Arabia
}

Received May 14, 2015; Accepted January 7, 2016

DOI: $10.3892 / \mathrm{mmr} .2016 .4903$

\begin{abstract}
In Saudi Arabia, the consumption of carbonated soft drinks is common and often occurs with each meal. Carbonated soft drink consumption has been shown to exhibit effects on the liver, kidney and bone. However, the effects of these soft drinks on brain activity have not been widely examined, particularly at the gene level. Therefore, the current study was conducted with the aim of evaluating the effects of chronic carbonated soft drink consumption on oxidative stress, brain gene biomarkers associated with aggression and brain histology. In total, 40 male Wistar rats were divided into four groups: Group 1 served as a control and was provided access to food and water ad libitum; and groups 2-4 were given free access to food and carbonated soft drinks only (Cola for group 2, Pepsi for group 3 and 7-UP for group 4). Animals were maintained on these diets for 3 consecutive months. Upon completion of the experimental period, animals were sacrificed and serological and histopathological analyses were performed on blood and tissues samples. Reverse transcription-polymerase chain reaction was used to analyze alterations in gene expression levels. Results revealed that carbonated soft drinks increased the serum levels of malondialdehyde (MDA). Carbonated soft drinks were also observed to downregulate the expression of antioxidants glutathione reductase (GR), catalase and glutathione peroxidase (GPx) in the brain when compared
\end{abstract}

Correspondence to: Professor Mohamed Mohamed Soliman, Department of Biochemistry, Faculty of Veterinary Medicine, Benha University, Moshtohur, Toukh, Benha, Qalyubia Governorate 13736, Egypt

E-mail: mohamedsoliman8896@yahoo.com

Key words: soft drinks, oxidative stress, brain activity, gene expression with that in the control rats. Rats administered carbonated soft drinks also exhibited decreased monoamine oxidase A (MAO-A) and acetylcholine esterase (AChE) serum and mRNA levels in the brain. In addition, soft drink consumption upregulated mRNA expression of dopamine D2 receptor (DD2R), while 5-hydroxytryptamine transporter (5-HTT) expression was decreased. However, following histological examination, all rats had a normal brain structure. The results of this study demonstrated that that carbonated soft drinks induced oxidative stress and altered the expression of certain genes that are associated with the brain activity and thus should be consumed with caution.

\section{Introduction}

Consumption of carbonated soft drinks is high in Saudi Arabia, particularly in middle-aged individuals aged between 35-50 years old. The effects of these products on health are unclear, although epidemiological studies have suggested their association with obesity, kidney disease, liver disease and osteoporosis $(1,2)$. They predominantly consist of water but also commonly contain phosphoric acid, caffeine, sugar and chemicals in the form of colorings, flavors, preservatives and sweeteners. The rate of consumption of these drinks is particularly high in affluent countries (1).

The majority of individuals view carbonated soft drink consumption as fairly innocuous (1). However, there are a number of serious health issues associated with regular consumption of carbonated soft drinks, for example, previous peer-reviewed studies have reported 25 separate harmful effects, including osteoporosis, and kidney and liver disease $(2,3)$. Carbonated soft drinks contain several compounds including caffeine; which is the most widely consumed behaviorally active substance worldwide. Almost all caffeine comes from dietary sources (4). Acute and chronic caffeine intake appear to have only minor negative consequences on health (5). For this reason and because few 
caffeine users report loss of control over their caffeine intake, governmental regulatory agencies impose no restrictions on its use. In the majority of carbonated beverages, caffeine is deliberately added to make it addictive. However, caffeine in carbonated drinks is more readily absorbed than that from other non-carbonated beverages. The majority of carbonated soft drinks also contain phosphoric acid, caffeine, sugar or aspartame or saccharin, caramel coloring, carbon dioxide, and aluminum. Each of which have been demonstrated to have negative effects on human health (5).

Caffeine is known to be an addictive drug that has the ability to stimulate mental alertness, overcome fatigue and enhance endurance. Caffeine acts by blocking adenosine (neurotransmitter) receptor sites in the central nervous system, and adenosine generally exhibits a depressant action in the brain, heart and kidneys. The resultant stimulation is accompanied by constriction of the cerebral arteries, elevated heartbeat, high blood pressure and excessive excretion of urine. Cases of caffeine-associated fatalities and seizures have previously been identified $(4,5)$ due to a combination of excess caffeine intake and cardiovascular disorders. Moreover, several studies have reported a weaker compensatory response after consumption of caloric liquids $(6,7)$. Previous studies have examined the effect of energy intake on brain histology and activity (6-9). It has been reported that soda exhibited an adverse effect on the cerebellum, whereas non-diet soda exhibited harmful effects (10).

In the Middle East, particularly in Saudi Arabia, it is common for individuals to consume carbonated soft drinks 3 times per day with each meal. Therefore, the current study was conducted to examine the effect of chronic consumption of three common drinks in Saudi Arabia (Cola, Pepsi and 7-UP) on oxidative stress, antioxidant levels, aggression markers, and histopathology of the brain to outline their potential effects on the brains of Wistar rats. In addition, the effect of soft beverages on the expression and activity of certain genes associated with anxiety, violence and/or aggression, such as monoamine oxidase (MAO) and dopamine D2 receptors (DD2R) were examined.

\section{Materials and methods}

Chemicals and kits. Ethidium bromide, agarose, Mayer's hematoxylin and eosin (H\&E) and Tris-Borate-EDTA (TBE) were purchased from Sigma-Aldrich (St. Louis, MO, USA). The Wistar albino rats were purchased from the King Fahd Center for Scientific Research, King Abdel-Aziz University (Jeddah, Saudi Arabia). Serologic kits for catalase, malondialdehyde (MDA), glutathione reductase (GR) and glutathione peroxidase (GPx) were purchased from Bio-diagnostic Co., (Giza, Egypt). Cola (Atlanta, GA, Pepsi (PepsiCo, Purchase, NY, USA) and 7-UP (Dr Pepper Snapple Group, Inc., Plano, TX, USA) were used. DNA $100 \mathrm{bp}$ ladder was purchased from MBI, Fermentas, Thermo Fisher Scientific. Inc. (Waltham, MA, USA). Qiazol for RNA extraction and oligo dT primers were purchased from Qiagen, Inc., (Valencia, CA, USA).

Animals, experimental design and sampling. All animal procedures were approved by the Ethical Committee Office of Taif University (Taif, Saudi Arabia). Forty male Wistar rats (age, 3 months; weight, 200-280 g) were used for this study. For acclimatization, animals were handled daily and kept under observation for 1 week prior to the onset of the experiment. The animals were kept under a 12-h light-dark cycle and had ad libitum access to food and water. Animals were divided into the following 4 groups: Control group (CNT) without any treatment; Cola group; Pepsi group and 7-UP group. Groups 2-4 received free access to food and only carbonated soft drinks for 3 consecutive months. At the end of the 3 months, all rats were anesthetized using diethyl ether inhalation and sacrificed via decapitation. Blood was collected in vacuteiner tubes from retro-orbital venous plexuses following anesthetization. Brain tissues from the right hemisphere were harvested for gene expression and left hemisphere tissues were used for histopathological analyses. Serum was extracted after blood centrifugation for $10 \mathrm{~min}$ at $4,000 \times \mathrm{g}$. For gene expression analysis, brain tissues were kept in QIAzol reagent at $-80^{\circ} \mathrm{C}$ for RNA extraction and in $10 \%$ neutral buffered formalin $(\mathrm{NBF})$ at room temperature for $24 \mathrm{~h}$ for histopathological and immunohistochemical analysis.

Serum chemistry assays. Catalase, GR, GP and MDA were measured using commercial spectrophotometric analysis kits (Bio-Diagnostic Company, Giza, Egypt). MAO and acetylcholine esterase (AChE) levels were measured using commercial enzyme-linked immunosorbent assay kits obtained from MyBioSource, Co. (San Diego, CA, USA). All procedures were conducted according to the manufacturer's protocol. mRNA expression levels of glutathione-S-transferase (GST) and 5-hydroxy tryptamine transporter (5-HTT) were assessed using reverse transcription-polymerase chain reaction (RT-PCR) analysis.

Gene expression analysis. Total RNA was extracted from the brain tissue samples as previously described (11). RNA concentration and purity were determined spectrophotometrically after measuring the optical density at 260 and $280 \mathrm{~nm}$ using a SmartSpec Plus spectrophotometer (Bio-Rad, Hercules, CA, USA). The RNA integrity was confirmed after running in $1.5 \%$ denatured agarose gel stained with ethidium bromide. A mixture of $3 \mu \mathrm{g}$ total RNA and $0.5 \mathrm{ng}$ oligo dT primer (Qiagen Inc., Valencia, CA, USA) were used for cDNA synthesis in a total volume of $11 \mu 1$ sterilized diethylpyrocarbonate (DEPC) water and was incubated in the Bio-Rad T100 Thermal cycler (Bio-Rad) at $65^{\circ} \mathrm{C}$ for $10 \mathrm{~min}$ for denaturation. Then, $2 \mu \mathrm{l}$ of 10X RT-buffer, $2 \mu \mathrm{l}$ of $10 \mathrm{mM}$ dNTPs and 100 units Moloney Murine Leukemia Virus Reverse Transcriptase (SibEnzyme. Ak, Novosibirsk, Russia) were added and made up to a total volume of $20 \mu \mathrm{l}$ with DEPC water. The mixture was then re-incubated in the thermal cycler at $37^{\circ} \mathrm{C}$ for $1 \mathrm{~h}$, then at $90^{\circ} \mathrm{C}$ for $10 \mathrm{~min}$ to inactivate the enzyme. For semi-quantitative RT-PCR analysis, specific primers for examined genes (Table I) were designed using the Oligo-4 computer program (version 7; Molecular Biology Insights, Colorado Springs, CO, USA) and synthesized by Macrogen (Macrogen Inc., Gasa-dong, Korea). PCR was conducted in a final volume of $25 \mu \mathrm{l}$ consisting of $1 \mu \mathrm{l}$ cDNA, $1 \mu 1$ of $10 \mathrm{pM}$ of each primer (forward and reverse), and 12.5 $\mu$ 1 PCR master mix (Promega Corporation, Madison, WI, USA), the volume was made up to $25 / \mu 1$ using sterilized deionized water. PCR was conducted using the Bio-Rad T100 
Table I. Polymerase chain reaction conditions and primers sequence of examined genes.

\begin{tabular}{|c|c|c|c|c|}
\hline Gene & Product size (bp) & Annealing & Direction & Sequence (5'-3') \\
\hline GST & 570 & 55 & $\begin{array}{l}\text { Forward } \\
\text { Reverse }\end{array}$ & $\begin{array}{l}\text { GCTGGAGTGGAGTTTGAAGAA } \\
\text { GTCCTGACCACGTCAACATAG }\end{array}$ \\
\hline GPx & 406 & 57 & $\begin{array}{l}\text { Forward } \\
\text { Reverse }\end{array}$ & $\begin{array}{l}\text { AAGGTGCTGCTCATTGAGAATG } \\
\text { CGTCTGGACCTACCAGGAACTT }\end{array}$ \\
\hline MAOA & 492 & 60 & $\begin{array}{l}\text { Forward } \\
\text { Reverse }\end{array}$ & $\begin{array}{l}\text { ATGGATGAAATGGGAAAAGAGAT } \\
\text { TAATTGGTTTCTCTCAGGTGGAA }\end{array}$ \\
\hline $\mathrm{AChE}$ & 785 & 55 & $\begin{array}{l}\text { Forward } \\
\text { Reverse }\end{array}$ & $\begin{array}{l}\text { GACTGCCTTTATCTTAATGTG } \\
\text { CGGCTGATGAGAGATTCATTG }\end{array}$ \\
\hline DD2R & 488 & 55 & $\begin{array}{l}\text { Forward } \\
\text { Reverse }\end{array}$ & $\begin{array}{l}\text { CCTGAGGACATGAAACTCTGC } \\
\text { TAGAGGACTGGTGGGATGTTG }\end{array}$ \\
\hline 5-HTT & 448 & 55 & $\begin{array}{l}\text { Forward } \\
\text { Reverse }\end{array}$ & $\begin{array}{l}\text { CTCTGGCTTCGTCATCTTCAC } \\
\text { GCTGCAGAACTGAGTGATTCC }\end{array}$ \\
\hline GAPDH & 309 & 52 & $\begin{array}{l}\text { Forward } \\
\text { Reverse }\end{array}$ & $\begin{array}{l}\text { AGATCCACAACGGATACATT } \\
\text { TCCCTCAAGATTGTCAGCAA }\end{array}$ \\
\hline
\end{tabular}

GST, glutathione-S-transferase; GPx, glutathione peroxidase; MAOA, monoamine oxidase A; AChE, acetylcholine esterase; DDR2, dopamine D2 receptor; 5-HTT, 5-hydroxytryptamine transporter; GAPDH, glyceraldehye 3-phosphate dehydrogenase.

A

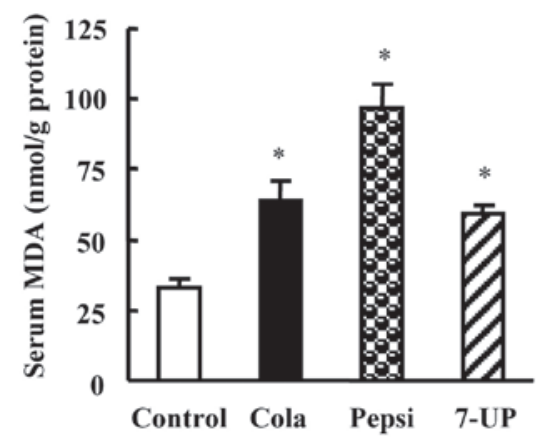

C

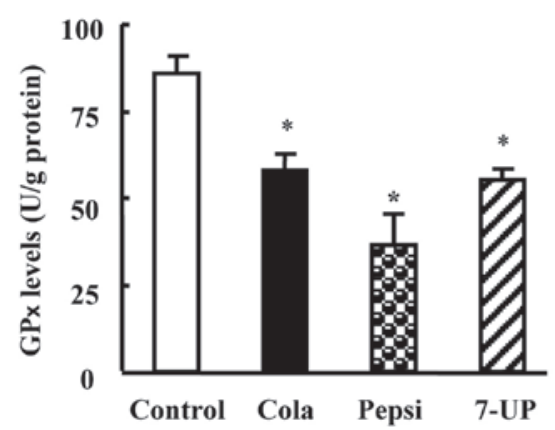

B

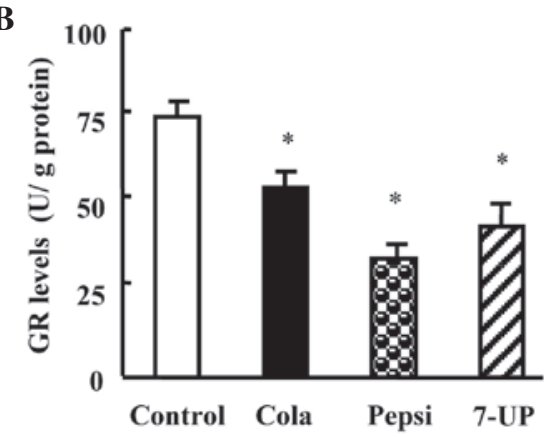

D

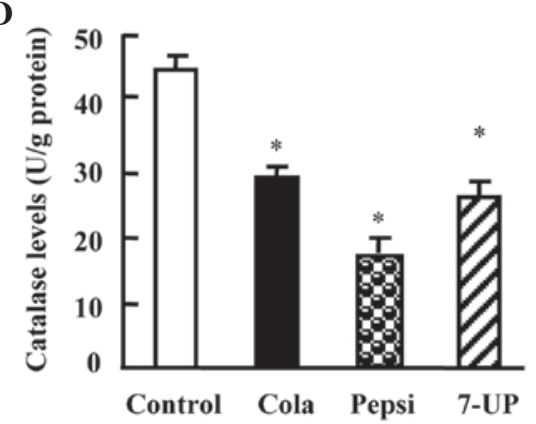

Figure 1. Serum changes in MDA and antioxidant levels in Wistar rats after chronic consumption of soft drinks for 3 months. Serum was assayed using colorimetric kits to determine the levels of (A) MDA, (B) GR, (C) GPx and (D) catalase. Values are presented as the mean \pm standard error of the mean for 10 rats per treatment. "P<0.05, compared with control. MDA, malondialdehyde; GR, glutathione reductase; GPx, glutathione peroxidase.

Thermal Cycler with the following cycle sequence: $94^{\circ} \mathrm{C}$ for $5 \mathrm{~min}$ for one cycle, followed by 27-31 cycles (Table I) each of which consisted of denaturation at $94^{\circ} \mathrm{C}$ for $1 \mathrm{~min}$, annealing at the specific temperature corresponding to each primer (Table I) and extension at $72^{\circ} \mathrm{C}$ for 1 min with an additional final extension at $72^{\circ} \mathrm{C}$ for $7 \mathrm{~min}$. As a reference, expression of glyceraldehyde-3-phosphate dehydrogenase
(GAPDH) mRNA was examined (Table I). PCR products were visualized under UV light after electrophoresis on $1.5 \%$ agarose (Bio Basic Int., Markham, ON, Canada) gel stained with ethidium bromide in TBE buffer. PCR products were confirmed using a 100 bp DNA ladder and were subsequently photographed using an InGenius 3.0 gel documentation system (Syngene, Frederick, MD, USA). The intensities of 

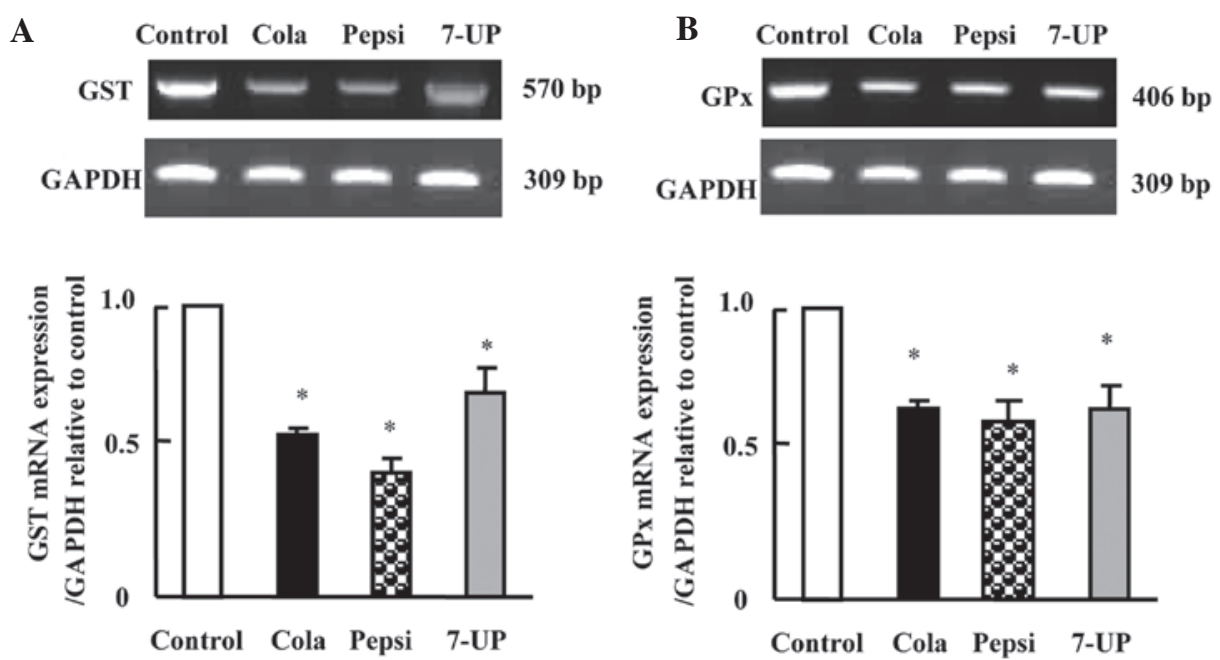

Figure 2. Semiquantitative-polymerase chain reaction analysis of GST and GPx expression in brain tissue after chronic administration of soft drinks for 3 months in Wistar rats. RNA was extracted and reverse transcribed (3 $\mu \mathrm{g})$ and RT-PCR analysis was conducted for (A) GST and (B) GPx genes. Densitometric analysis was conducted for 10 different rats. Values are presented as the mean \pm standard error of the mean. ${ }^{*} \mathrm{P}<0.05$ vs. control. GST, glutathione-S-transferase; GPX, glutathione peroxidase; GAPDH, glyceraldehyde-3-phosphate dehydrogenase.
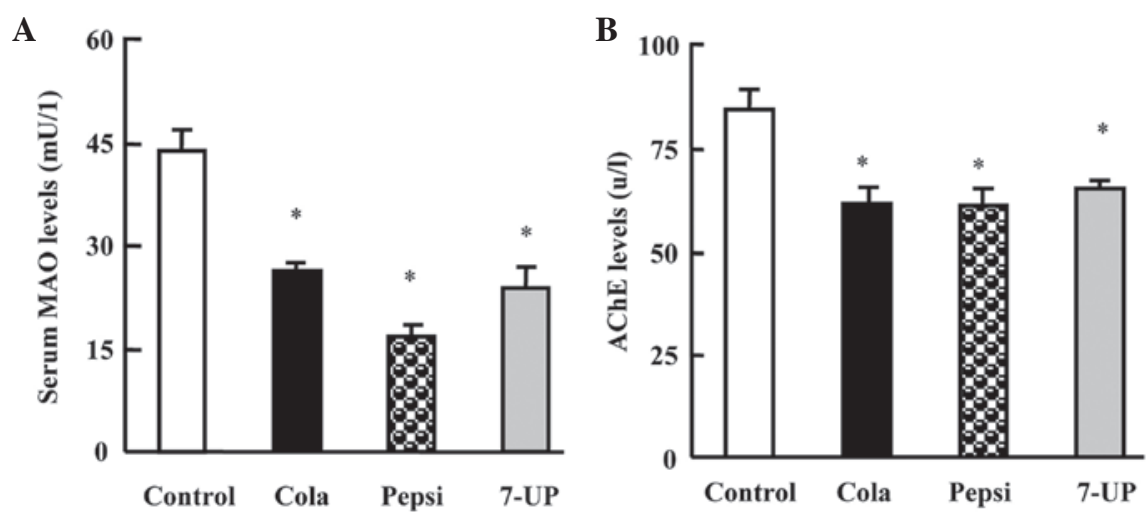

Figure 3. Serum changes in (A) MAO-A and (B) AChE levels in Wistar rats after chronic consumption of soft drinks for 3 months. Values are presented as the mean \pm standard error of the mean for 10 different rats per treatment. Serum was assayed using rat enzyme-linked immunosorbent assay kits. ${ }^{*} \mathrm{P}<0.05 \mathrm{vs}$. control. MAO, monoamine oxidase A; AChE, acetylcholine esterase.

the bands were quantified densitometrically using Image $\mathbf{J}$ software version 1.47 (http://imagej.en.softonic.com/).

Brain histopathology. Brain was removed following diethyl ether inhalation and sacrifice of the rats and fixed overnight in a $10 \%$ NBF solution. Fixed brain tissues were processed routinely, washed and preserved in 70\% ethanol, dehydrated in ascending grades of ethanol solution, cleared in xylene, embedded in paraffin wax, pressed and cut into $5-\mu \mathrm{m}$ sections. Subsequently, the sections were placed on top of glass slides. The slides were stained with Mayer's H\&E (12). Tissue slides were visualized using a Wolfe S9-0982 microscope (Carolina Biological Supply Co., Burlington, NC, USA) and photos were captured using a Canon Power-Shot SX500 IS digital camera (Canon, Tokyo, Japan).

Statistical analysis. Results are presented as the mean \pm standard error of mean. Data were analyzed using analysis of variance and Fisher post hoc descriptive tests using SPSS software version 11.5 (SPSS, Inc., Chicago, IL, USA).
Regression analysis was performed using the same software. $\mathrm{P}<0.05$ was considered to indicate a statistically significant difference.

\section{Results}

Effect of carbonated soft drink consumption for 3 months on serum levels of MDA, GR, GPX and catalase in Wistar rats. Consumption of Cola, Pepsi and 7-UP for 3 months showed a significant increase in MDA levels (Fig. 1A; $\mathrm{P}<0.05$ ) with the greatest increase in the rats from the Pepsi group. In parallel, the levels of antioxidants GR, GPx and catalase in the rats were decreased significantly in all groups administered carbonated soft drinks compared with the control. Notably, the greatest changes were observed in the rats from the Pepsi group (Fig. 1B-D).

Effect of carbonated soft drink consumption for 3 months on mRNA expression of GST and GPx in the brain tissues of Wistar rats. As shown in Fig. 2, carbonated soft drink 

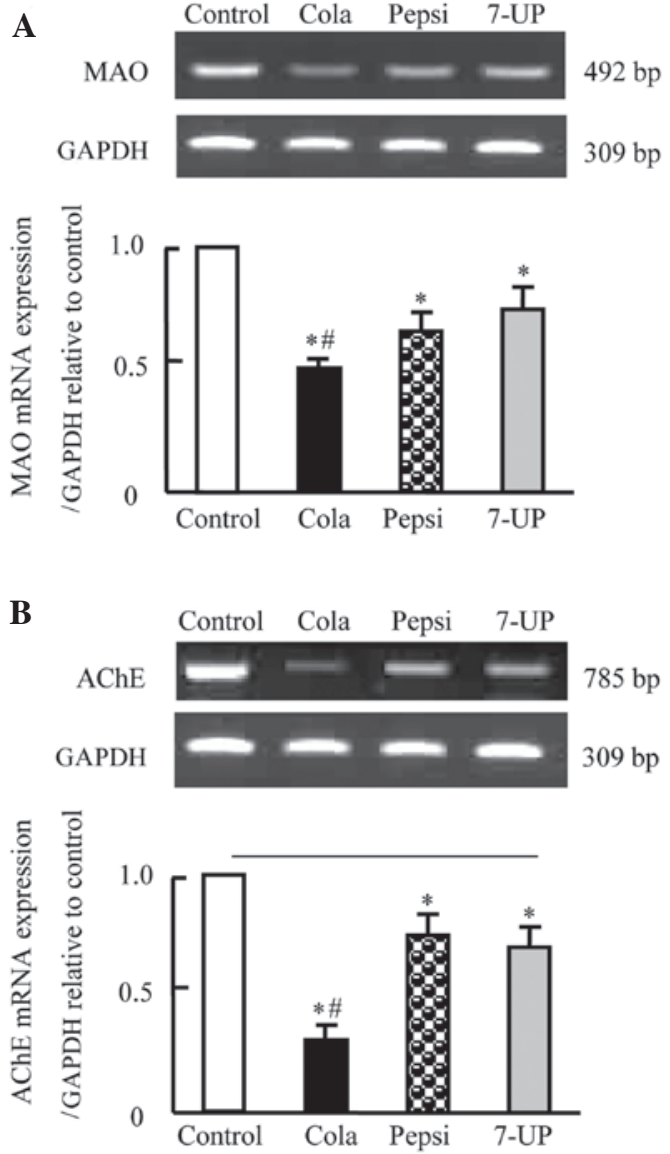

Figure 4. Semiquantitative reverse transcription-polymerase chain reaction analysis of (A) MAO-A and (B) AChE expression in brain tissue following chronic consumption of soft drinks for 3 months in Wistar rats. Densitometric analysis was conducted for 10 different rats. Values are presented as the mean \pm standard error of the mean. ${ }^{*} \mathrm{P}<0.05$ vs. control and ${ }^{\#} \mathrm{P}<0.05$ vs. the Pepsi and 7-UP groups. MAO, monoamine oxidase A; AChE, acetylcholine esterase; GAPDH, glyceraldehyde 3-phosphate dehydrogenase.

consumption for 3 months downregulated the mRNA expression of GST and GPx. Expression levels were significantly decreased by 50 and $40 \%$ in the Cola and Pepsi groups for GST and GPx, respectively $(\mathrm{P}<0.05)$. Although still significantly reduced when compared with the control $(\mathrm{P}<0.05)$, rats in the 7-UP group demonstrated increased levels of GST and GPx, as compared with the Cola and Pepsi groups.

Effect of carbonated soft drink consumption for 3 months on serum levels of MAO-A and AChE in Wistar rats. Next, the changes in MAO-A and AChE levels (Fig. 3) were examined. Cola, Pepsi and 7-UP consumption for 3 months resulted in a significant decrease in MAO and AChE levels $(\mathrm{P}<0.05)$. Rats in the Pepsi group exhibited the greatest decreases in MAO-A and AChE levels, as compared with the other groups.

Effect of carbonated soft drink consumption for 3 months on mRNA expression of MAO-A and AChE in brain tissues of Wistar rats. Fig. 4 shows that, consistent with serum changes of MAO-A and AChE, the mRNA expression of MAO-A and AChE was significantly downregulated in the brain tissues of rats administered carbonated soft drinks $(\mathrm{P}<0.05)$. Rats in the Cola group exhibited the greatest decrease in MAO-A and
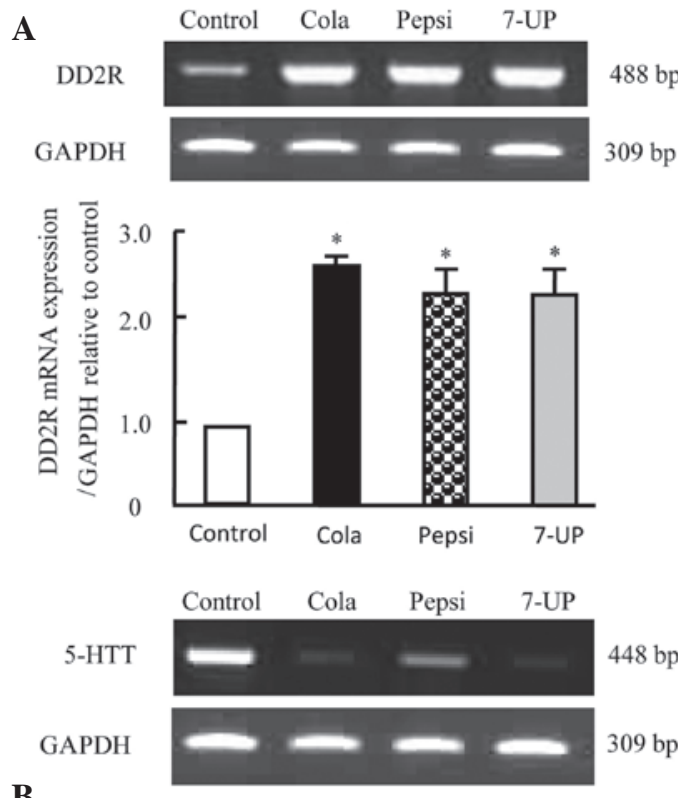

$\mathbf{B}$

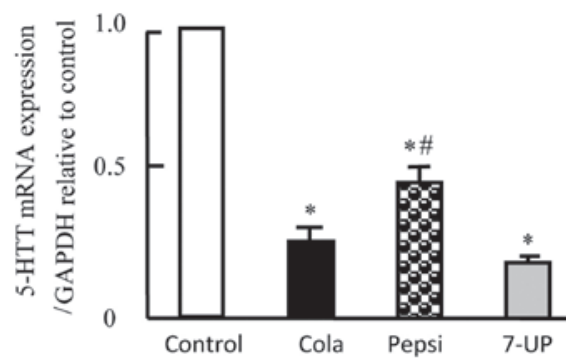

Figure 5. Semiquantitative reverse transcription-polymerase chain reaction analysis of (A) DD2R and (B) 5-HTT expression in brain tissue after chronic consumption of soft drinks for 3 months in Wistar rats. Densitometric analysis was conducted for 10 different rats. Values are presented as the mean \pm standard error of the mean. ${ }^{*} \mathrm{P}<0.05$ vs. control and ${ }^{\#} \mathrm{P}<0.05$ vs. the Cola and 7-UP groups. DD2R, dopamine D2 receptor; GAPDH, glyceraldehyde 3-phosphate dehydrogenase; 5-HTT, 5-hydroxytryptamine transporter.

AChE expression, followed by Pepsi and 7-UP, respectively. The decrease was not identified to be significantly different between the Pepsi and 7-UP groups (Fig. 4).

Effect of carbonated soft drink consumption for 3 months on mRNA expression of DD2R and 5-HTT in brain tissues of Wistar rats. The effects of carbonated soft drink consumption on the expression of certain genes that have been shown to be associated with aggression were investigated. As shown in Fig. 5A, expression of DD2R was significantly upregulated in rats in the Cola, Pepsi and 7-UP groups $(\mathrm{P}<0.05)$. By contrast, the rats in these groups exhibited significant downregulation of 5-HTT mRNA expression (Fig. 5B; P<0.05). Furthermore, rats in the Cola and 7-UP groups exhibited significantly decreased expression of 5-HTT, as compared with rats in the Pepsi group $(\mathrm{P}<0.05)$

Effect of carbonated soft drink consumption for 3 months on brain histopathology. Although changes induced by carbonated soft drinks were observed at the biochemical and molecular levels, brain histopathology analysis showed normal brain architecture in all groups (Fig. 6). The gray matter of the rats appeared normal with its well-organized regularly 

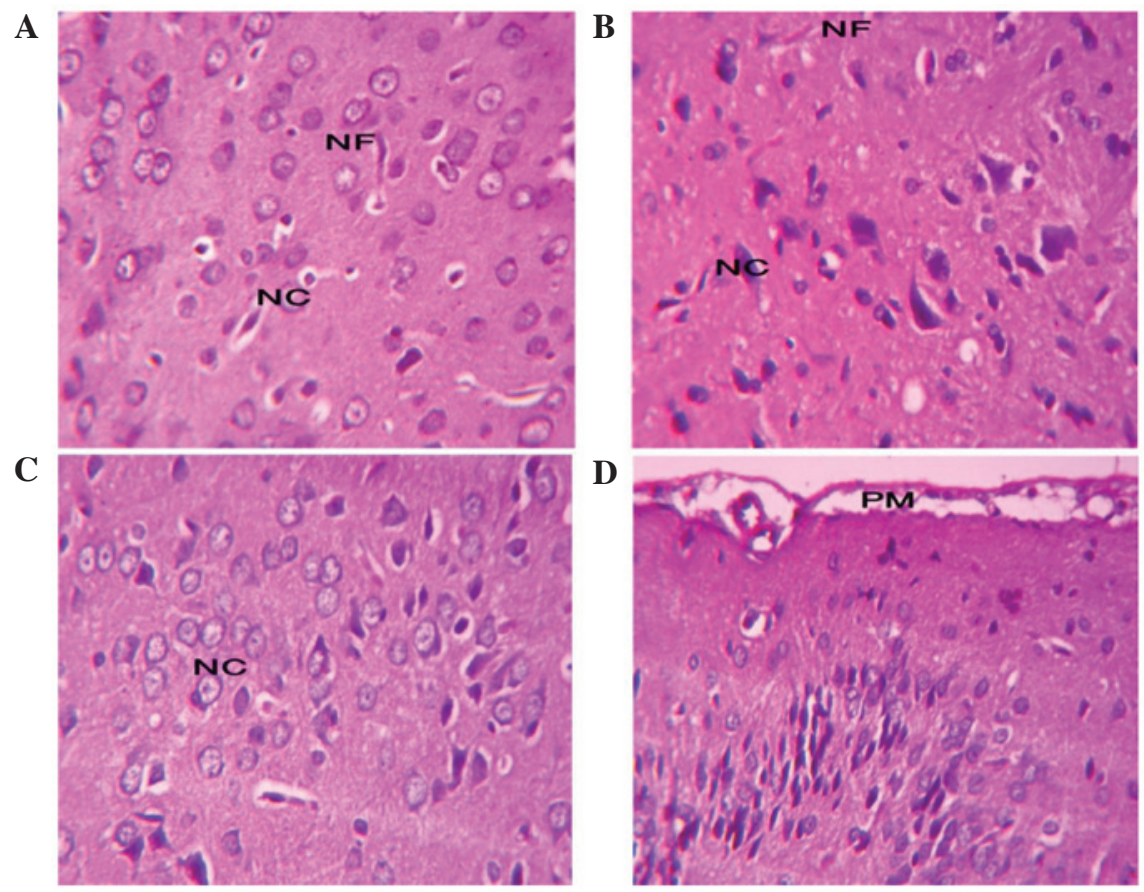

Figure 6. Photomicrographs of the brain in (A) the control group showing normal histological structure of the brain tissue. Different size and shape nerve cells and nerve fibers were observed. No histopathological changes were detected in (B) the Cola group, (C) the Pepsi group or (D) the 7-UP group. PM, pia mater; $\mathrm{NF}$, nerve fibers; NC, nerve cells. Stain, hematoxylin and eosin; magnification, $\mathrm{x} 40$.

arranged six layers and different size and shape nerve cells. The normal pattern of the white matter is formed of homogeneously stained nerve fibers running down the cortex was also identified.

\section{Discussion}

The results of current study confirmed that chronic consumption of carbonated soft drinks induced oxidative stress and changes in antioxidant expression in the brains of Wistar rats. Moreover, soft drink consumption decreased the serum levels and mRNA expression of MAO and AChE in the brain. Notably, it was also demonstrated that the levels of DD2R were downregulated and the levels of 5-HTT expression were upregulated in the brain, while brain histopathology remained unaffected.

Oxidative stress has been associated with the etiopathogenesis of several chronic diseases and exhibits a key role in the aging process (13). One of the consequences of uncontrolled oxidative stress (imbalance between the prooxidant and antioxidant levels in favor of prooxidants) is injury to cells, tissues and organs by oxidative damage. It has long been recognized that high levels of free radicals or reactive oxygen species (ROS) can directly damage lipids. The primary sources of endogenous ROS production are the mitochondria, plasma membrane, endoplasmic reticulum and peroxisomes (14). ROS are produced through a variety of mechanisms, including enzymatic reactions and/or auto-oxidation of several compounds, such as catecholamines and hydroquinone. In this study, chronic carbonated soft drink consumption induced oxidative stress in the brain as indicated by the increase in MDA levels in addition to the decrease in the expression of antioxidants, GR, GPx and catalase.
Carbonated soft drinks contain caffeine and phosphoric acid. Caffeine causes the release of adrenaline and an accompanying increase in blood sugar levels to produce the required energy. Caffeine reaches its peak level in the blood within $1 \mathrm{~h}$ of consumption and remains in the body for 4-6 $\mathrm{h}(4,5)$. Caffeine in soft drinks causes an increases in the release of acid into the stomach, which may lead to an upset stomach or heartburn. Moreover, caffeine has been reported that chronic exposure to the various components of energy and soft drinks may result in significant alterations in the cardiovascular system and brain activity $(15,16)$. The results of the present study demonstrated an alteration in MAO-A and $\mathrm{AChE}$ at the serum and mRNA levels. MAO has 2 isozymes, A and B. MAO-A in humans is encoded by the MAOA gene $(17,18)$. It preferentially deaminates norepinephrine, epinephrine, serotonin and dopamine (all are equally deaminated by MAO-A and MAO-B). Inhibition of both MAO-A and MAO-B using MAO inhibitor is used in the treatment of clinical depression, erectile dysfunction and anxiety. MAO-A has been shown to be increased in patients with depression (19) and an association has been demonstrated between low-activity forms of the MAO-A gene and autism (20). A dysfunctional MAO-A gene has also been correlated with increased aggression levels in mice $(21,22)$, as well as with heightened levels of aggression in humans (23). The results of the present study demonstrated that the consumption of carbonated soft drinks decreased MAO-A gene expression and were associated with oversensitivity, as MAO-A decrease is correlated with aggression and violence, this may suggest consumption of carbonated soft drinks is correlated with increased aggression and violence but this requires further investigation.

It is well-established that cholinergic neurons are involved in several neuropsychic functions, such as learning, memory 
and sleep. Acetylcholine exhibits a key role in modulating these functions (24). A central cholinergic deficit is strongly associated with certain neurodegenerative diseases, such as Alzheimer's disease and Parkinson's disease (25). Evidence of autism due to dysfunction of the cholinergic system has recently been reported (26). AChE is a specific cholinergic marker protein for the functional state of cholinergic neurons. It is key in the maintenance of acetylcholine levels at the cholinergic neurons (27) as it is responsible for degradation of acetylcholine to acetate and choline in the synaptic cleft. Notably, AChE was observed to be decreased in the serum and AChE mRNA expression was observed to be decreased in the brain. It has previously been suggested that acetylcholine disruption may be a primary cause of depression and/or aggression (28).

Dopamine is a neurotransmitter of the catecholamine and phenethylamine families that exhibits a number of roles in the human brain and body. There are 5 isoforms of the dopamine receptor, dopamine D1-5 receptors. DD2R is the most common receptor in the mammalian brain. DD2R antagonists have been used for decades to treat aggressive behavior in psychotic patients (29). In addition, in a preclinical study the role of dopamine D1, D2 and D3 receptors in the modulation of aggression has been documented (30). Several studies have indicated that the mesocorticolimbic dopamine system is involved in the preparation, execution and consequences of aggressive acts (31-33). Pharmacologically induced dopamine increases are associated with increased aggressive behavior under certain conditions $(32,33)$. The results of the present study demonstrated that DD2R levels increased following chronic carbonated soft drink consumption. This was probably due to the increase in dopamine levels resulting from the downregulation of MAO-A expression.

Two major enzymes are responsible for catecholamine catabolism in the brain: Catechol-O-methyltransferase (COMT) and monoamine oxidase A (MAO-A). If aggressive behavior is enhanced by catecholaminergic activity, then decreased activity of COMT and MAO-A should indirectly increase levels of aggression $(31,34)$.

5-HTT expression was shown to be downregulated following chronic carbonated soft drink consumption. A number of studies have shown that elevated serotonin levels lead to decreased aggression in a number of species (35), including humans (36). Blocking serotonin transporter molecules is effective in reducing and preventing aggressive behavior in humans and other animals, presumably due to increased brain 5-HT levels (35). Clinically, blocking 5-HTT with the administration of selective serotonin reuptake inhibitors (SSRIs), reduces aggressive outbursts and violent behavior in psychiatric patients (37-39). In addition, in animal models, acute and chronic treatment with SSRIs can dose-dependently reduce aggressive behavior (40). Acute administration of several SSRIs reduced aggression in different contexts and species, including rodents and non-human primates $(40,41)$. 5 -HTT is a type of monoamine transporter protein that transports serotonin from the synaptic cleft to the pre-synaptic neuron. This transport of serotonin by the 5-HTT protein terminates the action of serotonin and recycles it in a sodium-dependent manner. This protein is the target of numerous antidepressant agents, including those of the SSRI class (42). A repeat length polymorphism in the promoter of this gene has been shown to affect the rate of serotonin uptake and may exhibit a role in sudden infant death syndrome, aggressive behavior in Alzheimer disease patients, post-traumatic stress disorder and depression-susceptibility in individuals experiencing emotional trauma (43). It has also been suggested that alterations in 5-HTT expression levels following the consumption of carbonated soft drinks may be a predisposing factor for depression.

Histological examination of the brain revealed that the brain exhibited normal histology and cell distribution following chronic carbonated soft drink consumption. This finding was also reported in another study (10) for regular soft drinks; however, previously diet soft drinks were shown to exhibit adverse effects on the cerebellum of albino rats (10).

In conclusion, chronic term carbonated soft drink consumption induced oxidative stress and alterations in antioxidants and the expression levels of certain genes associated with brain function. Therefore, the results of the present study suggested that the consumption of carbonated soft drinks may induce adverse effects, thus these drinks must be consumed with caution.

\section{Acknowledgements}

The authors would like to thank Al-Saedan Research Chair for Genetic Behavioral Disorders, Taif University, Kingdom of Saudi Arabia, for their financial support.

\section{References}

1. Adjene JO, Ezeoke JC and Nwose EU: Histological effects of chronic consumption of soda pop drinks on kidney of adult Wister rats. N Am J Med Sci 2: 215-217, 2010.

2. Amato D, Maravilla A, García-Contreras F and Paniagua R: Soft-drinks and health. Rev Invest Clin 49: 387-395, 1997.

3. Amato D, Maravilla A, Montoya C, Gaja O, Revilla C, Guerra R and Paniagua R: Acute effects of soft drink intake on calcium and phosphate metabolism in immature and adults rats. Rev Invest Clin 50: 185-189, 1998.

4. Clauson KA, Shields KM, McQueen CE and Persad N: Safety issues associated with commercially available energy drinks. J Am Pharm Assoc (2003) 48: e55-e67, 2008.

5. Iyadurai SJ and Chung SS: New-onset seizures in adults: Possible association with consumption of popular energy drinks. Epilepsy Behav 10: 504-508, 2007.

6. DiMeglio DP and Mattes RD: Liquid versus solid carbohydrate: Effects on food intake and body weight. Int J Obes Relat Metab Disord 24: 794-800, 2000.

7. Mattes RD: Fluid energy-Where's the problem? J Am Diet Assoc 106: 1956-1961, 2006.

8. Frank GK, Oberndorfer TA, Simmons AN, Paulus MP, Fudge JL, Yang TT and Kaye WH: Sucrose activates human taste pathways differently from artificial sweetener. Neuroimage 39: 1559-1569, 2008.

9. Smeets PA, de Graaf C, Stafleu A, van Osch MJ and van der Grond J: Functional magnetic resonance imaging of human hypothalamic responses to sweet taste and calories. Am J Clin Nutr 82: 1011-1016, 2005.

10. Eluwa MA, Inyangmme II, Akpantah AO, Ekanem TB, Ekong MB, Asuquo OR and Nwakanma AA: A comparative study of the effect of diet and soda carbonated drinks on the histology of the cerebellum of adult female albino Wistar rats. Afr Health Sci 13: 541-545, 2013.

11. Soliman MM,Abdo Nassan M and Ismail TA:Immunohistochemical and molecular study on the protective effect of curcumin against hepatic toxicity induced by paracetamol in Wistar rats. BMC Complement Altern Med 14: 457, 2014.

12. Bancroft JD and Gamble M (eds.): Theory and practice of histological techniques. 6th ed. Churchill Livingstone Elsevier Philadelphia: pp126-127, 2008. 
13. Ceconi C, Boraso A, Cargnoni A and Ferrari R: Oxidative stress in cardiovascular disease: Myth or fact? Arch Biochem Biophys 420: 217-221, 2003.

14. Moldovan L and Moldovan NI: Oxygen free radicals and redox biology of organelles. Histochem Cell Biol 122: 395-412, 2004.

15. Higgins JP, Tuttle TD and Higgins CL: Energy beverages: Content and safety. Mayo Clin Proc 85: 1033-1041, 2010.

16. Usman A and Jawaid A: Hypertension in a young boy: An energy drink effect. BMC Res Notes 5: 591, 2012.

17. Hotamisligil GS and Breakefield XO: Human monoamine oxidase A gene determines levels of enzyme activity. Am J Hum Genet 49: 383-392, 1991.

18. De Colibus L, Li M, Binda C, Lustig A, Edmondson DE and Mattevi A: Three-dimensional structure of human monoamine oxidase A (MAO A): Relation to the structures of rat MAO A and human MAO B. Proc Natl Acad Sci USA 102: 12684-12689, 2005

19. Meyer JH, Ginovart N, Boovariwala A, Sagrati S, Hussey D, Garcia A, Young T, Praschak-Rieder N, Wilson AA and Houle S: Elevated monoamine oxidase a levels in the brain: An explanation for the monoamine imbalance of major depression. Arch Gen Psychiatry 63: 1209-1216, 2006.

20. Cohen IL, Liu X, Lewis ME, Chudley A, Forster-Gibson C, Gonzalez M, Jenkins EC, Brown WT and Holden JJ: Autism severity is associated with child and maternal MAOA genotypes. Clin Genet 79: 355-362, 2011

21. Scott AL, Bortolato M, Chen K and Shih JC: Novel monoamine oxidase A knock out mice with human-like spontaneous mutation. Neuroreport 19: 739-743, 2008

22. Vishnivetskaya GB, Skrinskaya JA, Seif I and Popova NK Effect of MAO A deficiency on different kinds of aggression and social investigation in mice. Aggress Behav 33: 1-6, 2007.

23. Brunner HG, Nelen M, Breakefield XO, Ropers HH and van Oost BA: Abnormal behavior associated with a point mutation in the structural gene for monoamine oxidase A. Science 262 . $578-580,1993$

24. Mohapel P, Leanza G, Kokaia M and Lindvall O: Forebrain acetylcholine regulates adult hippocampal neurogenesis and learning. Neurobiol Aging 26: 939-946, 2005.

25. Oda Y: Choline acetyltransferase: The structure, distribution and pathologic changes in the central nervous system. Pathol Int 49: 921-937, 1999.

26. Lam KS, Aman MG and Arnold LE: Neurochemical correlates of autistic disorder: A review of the literature. Res Dev Disabil 27: 254-289, 2006.

27. Eckenstein F and Sofroniew MV: Identification of central cholinergic neurons containing both choline acetyltransferase and acetylcholinesterase and of central neurons containing only acetylcholinesterase. J Neurosci 3: 2286-2291, 1983.

28. Shytle RD, Silver AA, Lukas RJ, Newman MB, Sheehan DV and Sanberg PR: Nicotinic acetylcholine receptors as targets for antidepressants. Mol Psychiatry 7: 525-535, 2002.
29. Glazer WM and Dickson RA: Clozapine reduces violence and persistent aggression in schizophrenia. J Clin Psychiatry 59 (Suppl 3): 8-14, 1998

30. Miczek KA, Covington HE III, Nikulina EM Jr and Hammer RP: Aggression and defeat: Persistent effects on cocaine self-administration and gene expression in peptidergic and aminergic mesocorticolimbic circuits. Neurosci Biobehav Rev 27: 787-802, 2004

31. de Almeida RM, Ferrari PF, Parmigiani S and Miczek KA: Escalated aggressive behavior: Dopamine, serotonin and GABA. Eur J Pharmacol 526: 51-64, 2005.

32. Ferrari PF, van Erp AM, Tornatzky W and Miczek KA: Accumbal dopamine and serotonin in anticipation of the next aggressive episode in rats. Eur J Neurosci 17: 371-378, 2003.

33. Ferrari PF, Palanza P, Parmigiani S, de Almeida RM and Miczek KA: Serotonin and aggressive behavior in rodents and nonhuman primates: Predispositions and plasticity. Eur J Pharmacol 526: 259-273, 2005.

34. Gogos JA, Morgan M, Luine V, Santha M, Ogawa S, Pfaff D and Karayiorgou M: Catechol-O-methyltransferase-deficient mice exhibit sexually dimorphic changes in catecholamine levels and behavior. Proc Natl Acad Sci USA 95: 9991-9996, 1998.

35. Chiavegatto $\mathrm{S}$ and Nelson RJ: Interaction of nitric oxide and serotonin in aggressive behavior. Horm Behav 44: 233-241, 2003.

36. Coccaro EF and Kavoussi RJ: Neuropsychopharmacologic challenge in biological psychiatry. Clin Chem 40: 319-327, 1994.

37. Barkan T, Peled A, Modai I, Barak P, Weizman A and Rehavi M: Serotonin transporter characteristics in lymphocytes and platelets of male aggressive schizophrenia patients compared to non-aggressive schizophrenia patients. Eur Neuropsychopharmacol 16: 572-579, 2006.

38. Blader JC: Pharmacotherapy and postdischarge outcomes of child inpatients admitted for aggressive behavior. J Clin Psychopharmacol 26: 419-425, 2006.

39. Bond AJ: Antidepressant treatments and human aggression. Eur J Pharmacol 526: 218-225, 2005.

40. Carrillo M, Ricci LA, Coppersmith GA and Melloni RH Jr: The effect of increased serotonergic neurotransmission on aggression: A critical meta-analytical review of preclinical studies. Psychopharmacology (Berl) 205: 349-368, 2009.

41. Caldwell EE and Miczek KA: Long-term citalopram maintenance in mice: Selective reduction of alcohol-heightened aggression. Psychopharmacology (Berl) 196: 407-416, 2008.

42. Deutch AY and Roth RH: Neurotransmitters In: Fundamental Neuroscience. Squire L, Berg S, Bloom F, du Lac S, Ghosh A and Spitzer N (eds). 3rd edition. Elsevier/Academic Press, Amsterdam, pp143, 2008.

43. Holmes A, Murphy DL and Crawley JN: Reduced aggression in mice lacking the serotonin transporter. Psychopharmacology (Berl) 161: 160-167, 2002. 